\title{
1 Lymph drainage from the ovine tonsils: an anatomical study of the tonsillar
}

\section{2 lymph vessels}

4 C. Casteleyn ${ }^{1 *}$, P. Cornillie ${ }^{1}$, C. Van Ginneken ${ }^{2}$, P. Simoens ${ }^{1}$, S. Van Cruchten ${ }^{2}$, K.

$5 \quad$ Vandevelde $^{1}$, W. Van den Broeck ${ }^{1}$

6

$7{ }^{1}$ Department of Morphology, Faculty of Veterinary Medicine, Ghent University,

8 Salisburylaan 133, 9820 Merelbeke, Belgium

$9 \quad{ }^{2}$ Laboratory of Applied Veterinary Morphology, Department of Veterinary Sciences, Faculty

10 of Pharmaceutical, Biomedical and Veterinary Sciences, University of Antwerp,

11 Universiteitsplein 1, 2610 Wilrijk, Belgium

12

$13 *$ Corresponding author with present address: Laboratory of Applied Veterinary Morphology,

14 Department of Veterinary Sciences, Faculty of Pharmaceutical, Biomedical and Veterinary

15 Sciences, University of Antwerp, Wilrijk, Belgium. Tel.: +32 3-265-28-21; fax: +32 3-265-

16 24-33; e-mail: Christophe.Casteleyn@ua.ac.be (C. Casteleyn)

17

18 With 6 figures 


\section{Summary}

20 Although the tonsils of sheep have gained much attention during the last decade, only few 21 data are available on their lymph vessel architecture. Tonsillar lymph vessels are immunologically important as they form the efferent routes for locally activated immune cells to reach the draining lymph nodes. To gain insight into the tonsillar lymph drainage in the sheep, Indian ink and a casting polymer were injected into the interstitium of the five tonsils present in the heads of slaughtered sheep. This enabled to determine the draining lymph node and to examine the microscopic organization of lymph vessels using light and scanning electron microscopy. No lymph vessels were observed within the tonsillar lymphoid follicles. The corrosion casts demonstrated that the lymphoid follicles are surrounded by numerous sacculated lymph sinuses that drain into a dense interfollicular lymph vessel network. From

30 here the lymph flows into single small lymph vessels that in turn drain into larger lymph vessels extending towards the medial retropharyngeal lymph node. The presented results can be valuable for immunological studies, e.g. during oral or intranasal vaccine development.

34 Keywords: Sheep; Tonsils; Lymph drainage; Lymph vessels; Corrosion cast 


\section{Introduction}

Immune responses against ingested and inhaled foreign antigens are initiated in the tonsils since these mucosa-associated lymphoid tissues (MALT) are the body's most proximal line of defence (Casteleyn et al., 2007; Brandtzaeg, 2011; Maunsell et al., 2012). Besides maintaining pharyngeal immunity, locally activated antigen-specific $\mathrm{T}$ and $\mathrm{B}$ lymphocytes can migrate from the tonsils towards distant MALT sites such as the Peyer's patches (Brandtzaeg and Pabst, 2004; Kuper, 2006). To this purpose, the lymphocytes leave the tonsils via efferent lymph vessels, subsequently drain into the blood circulation and finally enter immunological effector sites by diapedesis through high endothelial venules (HEVs) (Indrasingh et al., 2002; Cesta, 2006; Liebler-Tenorio and Pabst, 2006). As such, lymph vessels and HEVs form the structural basis of the integrated mucosal immune system since they provide the routes for lymphocyte circulation between different MALT sites (Belz and Heath, 1995; Girard and Springer, 1995; Rothkötter et al., 1995; Belz, 1998).

During the past decade the tonsils of sheep have received particular interest within the scope of prion diseases (Schreuder et al., 1998; Van Keulen et al., 2008). To aid the unravelling of the pathogenesis of transmissible spongiform encephalopathies (TSEs), morphological and immunological data on the five ovine tonsils, including the paired palatine tonsil (tonsilla (t.) palatina) located in the oropharynx, the paired paraepiglottic tonsil (t. paraepiglottica) in the laryngopharynx, and the tonsil of the soft palate (t. veli palatina), the pharyngeal tonsil (t. pharyngea) and the paired tubal tonsils (t. tubaria) in the nasopharynx (Casteleyn et al., 2007, 2011a; Breugelmans et al., 2011a), were gathered. The exact anatomical localizations, histological characteristics, volumes and surface areas, distribution of lymphoid cell populations, and innervation of the ovine tonsils have yet been described (Russo et al., 2009; Casteleyn et al., 2007, 2008a, 2010a; Breugelmans et al., 2011a, 2011b, 2011c; Toppets et al., 2012). 
Remarkably, only few data are available on the lymphatic system of the ovine tonsils. Indeed, many conventional anatomical handbooks do not mention the lymphatic drainage from the tonsils (Martin and Schauder, 1938; Grau-Karlsbad, 1974; Saar and Getty, 1975; Vollmerhaus, 1976; König et al., 2002; Gille, 2008). Moreover, when literature data are available, they are inconsistent or only general in nature, without mentioning species-specific characteristics. For example, according to Berg (1988) the lymph from the tonsils of the common domestic mammals is conveyed to the mandibular lymph centre, while Barone (1996) states that all tonsillar lymph flows directly to the retropharyngeal lymph centre.

Detailed, species-specific knowledge of the tonsillar lymphatic system can be valuable for immunological studies, e.g. during oral or intranasal vaccine development investigating the generation of antigen-specific lymphocytes (Casteleyn et al., 2013). The usefulness of such mucosal vaccines is illustrated by the successful eradication of human polio by oral vaccination (Murphy et al., 2008). Veterinary examples of potent intranasal vaccination include the vaccines against kennel cough in the dog, bovine and feline rhinotracheitis, Streptococcus equi infections in horses, and infectious bronchitis and Newcastle disease in poultry (Tizard, 2013). Besides the induction of mucosal immunity at the sites of potential infection, immune cells activated in the tonsils by mucosal vaccines use the efferent tonsillar lymph vessels to migrate towards the draining lymph node where serum IgG antibodies, providing systemic immunity, are secreted (Kuper et al., 1992; Zuercher, 2003).

In the framework of assessing the effectiveness of a newly developed mucosal vaccine, it is important to identify the lymph nodes draining the ovine tonsils. In line with this, the intratonsillar distribution of the lymph vessels should be investigated to gain insight in the emigration of activated lymphocytes into the tonsillar lymphatic system. In contrast to the well described distribution of lymph vessels within lymph nodes (Heath et al., 1986; Heath and Spalding, 1987; Azzali, 2003), descriptions of the lymphatic systems present in MALT 
sites are restricted to the human and canine palatine tonsils, the Peyer's patches of the rabbit, guinea pig, mouse, sheep and pig, and the vermiform appendix of the rabbit (Ohtani and Murakami, 1990; Lowden and Heath, 1992, 1994; Belz and Heath, 1995; Regoli et al., 1995; Fujisaka et al., 1996; Azzali, 1998; Azzali et al., 2002; Azzali, 2003).

Since data on the lymphatic system of the ovine tonsils are largely lacking and ambiguous, the aims of the present study were to identify the draining lymph node(s) and to describe the microstructure of the tonsillar lymphatic system in the sheep. The research methods included interstitial injection of Indian ink and casting polymer into the five ovine tonsils, combined with light and scanning electron microscopy (SEM).

\section{Materials and Methods}

\section{Lymph drainage from the tonsils}

The heads of five healthy one-year-old Texel sheep were collected at a local abattoir. Using a band saw, they were longitudinally sectioned $1 \mathrm{~cm}$ lateral to the median plane in order not to transect the pharyngeal tonsil located at the caudal end of the pharyngeal septum (Casteleyn et al., 2007, 2008a). Indian ink (Pelikan black 17 Fount India, Pelikan Benelux N.V., GrootBijgaarden, Belgium) was interstitially injected into the centre of each tonsil (ten palatine, paraepiglottic and tubal tonsils, and five pharyngeal tonsils and tonsils of the soft palate) via a 26 gauge $(\mathrm{G})$ needle inserted just underneath the tonsillar epithelium (Castenholz, 1984, 1986; Lowden and Heath, 1992, 1993; Casteleyn et al., 2007, 2008b). A volume of $0.5 \mathrm{ml}$ ink was injected into the largest ovine tonsil, i.e. the pharyngeal tonsil (Casteleyn et al., 2007). The second largest tonsil, being the palatine tonsil, was injected with $0.3 \mathrm{ml}$ ink, while all other, small, tonsils received $0.1 \mathrm{ml}$ ink (Casteleyn et al., 2007). Subsequently, the heads were dissected to demonstrate black stained lymph vessels emerging from the injected tonsils and coursing towards either the parotid, mandibular or retropharyngeal lymph nodes. These lymph 
110 nodes were examined both macroscopically and histologically using a light microscope

111 (Olympus BX 61, Olympus Belgium, Aartselaar, Belgium) for the appearance of black

112 staining and the presence of carbon particles, respectively (Casteleyn et al., 2008b). For

113 histological analysis, the lymph nodes were fixated in $3.5 \%$ neutral buffered formaldehyde for

114 two days at room temperature. They were then routinely processed to a series of 10

115 histological sections, cut at fixed intervals throughout the entire lymph nodes that were

116 stained with haematoxylin and eosin (HE).

117

118 Light microscopy on the tonsils after interstitial injection of Indian ink

119 The interstitially injected tonsils were excised and fixated in $3.5 \%$ neutral buffered

120 formaldehyde for two days at room temperature. The fixated samples were routinely

121 processed to a series of $10 \mathrm{HE}$-stained histological sections, cut at fixed intervals throughout

122 the entire tonsils. The presence and distribution of carbon particles were examined by light

123 microscopy (Olympus BX 61).

124

125

SEM on corrosion casts of the tonsillar lymphatic system

126 The heads of an additional number of five healthy one-year-old Texel sheep were collected at

127 a local abattoir. Each tonsil was interstitially injected via a $26 \mathrm{G}$ needle inserted just 128 underneath the tonsillar epithelium with, according to the size of the tonsil as described 129 above, $0.1 \mathrm{ml}$ to $0.5 \mathrm{ml}$ Mercox $\mathrm{II}^{\circledR}$ (methyl methacrylate-based casting medium, Ladd 130 Research, Williston, USA). After polymerization, which took approximately $15 \mathrm{~min}$, the 131 casted tonsils were excised and macerated overnight in $25 \% \mathrm{KOH}$ (Carl Roth $\mathrm{GmbH}$,

132 Karlsruhe, Germany). The obtained lymphatic casts were gently rinsed with distilled water, 133 air dried, coated with platinum and examined with SEM (JEOL JSM 5600 LV, Jeol, 134 Zaventem, Belgium). 


\section{Results}

137

\section{Lymph drainage from the tonsils}

Indian ink that was injected superficially into each of the five ovine tonsils drained directly to the medial retropharyngeal lymph node in all five examined animals. The afferent lymph vessels to this lymph node were easily distinguishable by their black colour (Fig. 1A). At the surface of the lymph node they divided into primary branches, giving off secondary ramifications that in turn divided into tertiary or terminal branches. The latter terminated in the subcapsular sinus of the lymph node (Fig. 1B).

\section{Light microscopy on the tonsils after interstitial injection of Indian ink}

After interstitial injection of Indian ink into the tonsils, carbon particles were abundantly present in the lymph vessels located in between neighbouring lymphoid follicles (Fig. 2A). As such, an interfollicular lymph vessel network surrounding the lymphoid follicles could be observed. Only limited amounts of carbon particles were seen within the lymphoid follicles

(Fig. 2B). These carbon particles seemed not to be enclosed by endothelium-lined vessels, but appeared as free particles lying in the interstitial spaces between the densely packed lymphocytes composing the lymphoid follicles. The interfollicular lymph vessel network drained into larger lymph vessels that were present in the connective tissue underneath the scatered lymphoid follicles located in the tonsil of the soft palate and in the paraepiglottic and tubal tonsils. Larger lymph vessels also coursed through the connective tissue core of the pharyngeal tonsil, and through the connective tissue septa of the palatine tonsil (Fig. 2A). Blood vessels, containing erythrocytes, contrasted well with the lymph vessels by their lack of carbon particles (Fig. 2B). 
161 At low magnification round impressions were visible at the surfaces of the casts from the 162 palatine, paraepiglottic and pharyngeal tonsils (Figs. 3-5). The diameters of these impressions

163 that are located just underneath the tonsillar epithelium amounted to approximately $500 \mu \mathrm{m}$.

164 These data combined with the histological images presented in Fig. 2 demonstrate that the 165 round impressions represent the locations of lymphoid follicles in unmacerated tonsils. No

166 indications for the presence of intraepithelial lymph vessels were noticed on the corrosion casts. At higher magnification sacculated lymph sinuses were observed at the bottom and the sides of the lymphoid follicles. In between these follicles a finely-meshed interfollicular

169 lymph vessel network, characterized by numerous cellular impressions, was present (Fig. 5).

170 Some distinct lymph vessels extended through the interfollicular regions and connected to

171 larger efferent lymph vessels that emerged from the tonsils. Deeply indented, V-shaped 172 constrictions were visible at intervals of approximately $500 \mu \mathrm{m}$ in larger lymph vessels 173 travelling through the connective tissue cores and septa of tonsils and in those running in the 174 subepithelial connective tissue towards the draining lymph node (Figs. 5 and 6).

175 Since the tubal tonsils and the tonsils of the soft palate only contain scattered lymphoid 176 follicles, impressions could not be recognized on the surfaces of their casts (Fig. 6) (Casteleyn 177 et al., 2007). The interstitial spaces on the nasopharyngeal side of the soft palate and the 178 lateral nasopharyngeal mucosa were recognized on the casts by their numerous cellular 179 impressions. The interstitium drained into small lymph vessels that merged into larger lymph 180 vessels. These vessels extended in rostrocaudal direction towards the medial retropharyngeal 181 lymph nodes and showed deeply indented, often V-shaped constrictions (Fig. 6). 
184 The present study describes the lymph drainage from the $t$. palatina, $t$. paraepiglottica, $t$. 185 pharyngea, t. tubaria and t. veli palatini. Although an additional, lingual tonsil has been 186 decribed in the sheep (Casteleyn et al., 2007, 2011b), this tonsil was not included since it only 187 consists of small non-organized aggregations of lymphoid cells mainly located in the centres 188 of the vallate papillae at the root of the tongue (Casteleyn et al., 2007; Breugelmans et al., 189 2011a).

190 The data presented here are morphological in nature, but aim to contribute to the 191 knowledge of the mucosal immune system as well. In order to correspond to the commonly 192 used immunological terminology, the official anatomical terms defining a well-circumscribed 193 aggregation of lymphoid cells, i.e. lymph nodule, lymphonodulus or nodulus lymphaticus, 194 were replaced by the immunological term lymphoid follicle (Casteleyn et al., 2011a).

195 During the interstitial injections with Indian ink in the centres of the tonsils it was macroscopically observed that the injected volumes were sufficient to allow spreading of the

197 ink towards the periphery of the tonsils. The lymph, in our experiments represented by ink, 198 drained directly from each tonsil to the medial retropharyngeal lymph node. Since all 199 experiments were performed on slaughtered animals, this draining was due to the manual 200 pressure by which the liquids were injected. It is plausible that swallowing enhances lymph 201 drainage from the ovine tonsils in vivo. In this respect, the V-shaped indentations that were 202 observed on the casted larger lymph vessels, that are suggestive of lymphatic valves 203 (Castenholz, 1986), are meaningful. The application of manual pressure during the injections 204 of ink might have forced carbon particles into the interstitium of lymphoid follicles, as 205 suggested by Fig. 2B. The high cellular density of lymphoid follicles could explain the 206 presence of only limited amounts of intrafollicular carbon particles. These particles could also 207 be present in small intrafollicular lymph vessels, but this was not be demonstrated on the 208 corrosion casts. In addition, other authors also state that no lymph vessels are present within 
lymphoid follicles (Ohtani and Murakami, 1990; Lowden and Heath, 1992, 1994; Belz and

210 Heath, 1995; Regoli et al., 1995; Fujisaka et al., 1996; Azzali, 1998; Azzali et al., 2002;

211 Azzali, 2003).

212 For the preparation of the corrosion casts, Mercox ${ }^{\circledR}$ was used since its very low viscosity is

213 highly advantageous for interstitial injection and casting of capillary structures (Hodde, 1981;

214 Murakami et al., 1984). Unfortunately, Mercox ${ }^{\circledR}$ casts are very brittle and thus have to be

215 handled with care. Another disadvantage is that Mercox ${ }^{\circledR}$ is approximately twice as expensive

216 as Batson's ${ }^{\circledR}$ (Polysciences, Warrington, USA). The latter casting polymer is also based on

217 methyl methacrylate, but has a much higher viscosity than Mercox ${ }^{\circledR}$. It is therefore commonly

218 used to cast larger blood vessels and other lumen containing structures such as the avian air

219 sacs (Konerding, 1991; Casteleyn et al., 2010b; Stefanov et al., 2013).

220 The distribution of the injected Mercox ${ }^{\circledR}$ was similar to that of the Indian ink. Its low

221 viscosity also enabled the polymer to course towards the medial retropharyngeal lymph nodes.

222 The scanning electron microscopic knowledge obtained in the present study concerning the

223 lymph vessel organization of the ovine tonsils correspond with the data presented by other

224 authors investigating the lymph vessel organization of the human and canine palatine tonsils,

225 the Peyer's patches of the rabbit, guinea pig, mouse, sheep and pig, and the rabbit vermiform

226 appendix (Ohtani and Murakami, 1990; Lowden and Heath, 1992, 1994; Belz and Heath,

227 1995; Regoli et al., 1995; Fujisaka et al., 1996; Azzali, 1998; Azzali et al., 2002; Azzali, 228 2003).

229 The parotid and mandibular lymph nodes did not receive Indian ink. Our observation 230 therefore contrasts with the statement of Berg (1988) that all tonsillar lymph flows to the 231 mandibular lymph centre, but corresponds with the data presented by Barone (1996). These 232 lymph nodes therefore seem to play no role in the induction of immunity after antigen uptake 233 at tonsillar epithelia, e.g. by M cell-like cells (Casteleyn et al., 2010a, 2013). Since tonsils 
234 lack afferent lymph vessels (Mair et al., 1987; Chen et al., 1989; Indrasingh et al., 2002), it is 235 not surprising that lymph vessels connecting different tonsils were not observed. Thus, no 236 lymphatic connection between the different tonsillar structures of Waldeyer's ring exists (Von 237 Waldeyer-Hartz, 1884).

238 It should be noted that the results presented here have been obtained in Texel sheep. Since 239 this ovine breed is reared for meat production, tissues from Texel sheep are easily collected at 240 the slaughterhouse. This breed is therefore very valuable for ex vivo experiments. To the best 241 of our knowledge, no anatomical studies investigating the lymph drainage from the tonsils in 242 other ovine breeds have yet been performed. As a result, no statement on the existence of 243 breed related anatomical variations can be made. However, it is not plausible that the general 244 pattern of lymph drainage from the tonsils, i.e. collection of interstitial fluid into small lymph 245 vessels that convey into larger lymph vessels flowing towards the medial retropharyngeal 246 lymph node, differs between various ovine breeds.

247 Immunocompetent cells deriving from those tonsils that are considered as the main 248 inductive sites for mucosal immunity in the sheep, i.e. the palatine and pharyngeal tonsils 249 (Breugelmans et al., 2011b) as well as lymphocytes activated in the medial retropharyngeal 250 lymph node by drained antigens all emigrate together with secreted systemic antibodies 251 produced in the draining lymph node (Kuper et al., 1992; Zuercher, 2003) via efferent lymph 252 vessels towards the ipsilateral lateral retropharyngeal lymph nodes (Schummer et al., 1981; 253 Barone, 1996). From here, the lymph flows in the ipsilateral tracheal trunks that extend 254 towards the deep caudal cervical lymph nodes located at the ventral side of the trachea near 255 the median plane (Barone, 1996). Finally, the lymph from these lymph nodes is conveyed in 256 the common duct of the two tracheal trunks which discharge by a variable pattern in the 257 cranialmost segment of the cranial vena cava at the thoracic inlet (Schummer et al., 1981; 258 Barone, 1996). These anatomical structures thus provide the route for antigen-specific 
259 lymphocytes and antibodies to reach the systemic circulation, enabling them to travel to and 260 protect distant MALT sites.

\section{Conclusions}

263 The tonsillar lymphatic system in the sheep is well-developed. It is composed of 264 interfollicular lymph vessel networks draining into single small lymph vessels that join to 265 form larger efferent lymph vessels containing valves. All efferent lymph vessels from each of 266 the five ovine tonsils drain to the retropharyngeal lymph centre. The other cranial lymph 267 centres, i.e. the parotid and mandibular lymph centres, play no role in the induction of 268 immunity against harmful antigens sampled at the tonsillar surfaces.

\section{Acknowledgements}

271 The authors are grateful to the slaughterhouse Isla-Meat (Lennik, Belgium) for supplying the

272 sheep heads. The technical assistance of P. Vervaet and L. Standaert is kindly acknowledged.

\section{References}

275 Azzali, G., 1998: Three-dimensional and ultrastructural aspects of the lymphatic vascularization of the vermiform appendix. J. Submicrosc. Cytol. Pathol. 30, 545-553.

277 Azzali, G., 2003: Structure, lymphatic vascularization and lymphocyte migration in mucosa278 associated lymphoid tissue. Immunol. Rev. 195, 178-189.

279 Azzali, G., M. Vitale, and M. L. Arcari, 2002: Ultrastructure of absorbing peripheral 280 lymphatic vessel (ALPA) in Guinea pig Peyer's patches. Microvasc. Res. 64, 289-301.

281 Barone, R., 1996: Anatomie Comparée des Mammifères Domestiques, Tome Cinquième: 282 Angiologie (R. Barone ed). Paris: Éditions Vigot. 
Belz, G. T., 1998: An unusual structure of venules in tonsils of the soft palate of young pigs. J. Anat. 192, 131-135.

Belz, G. T., and T. J Heath, 1995: Lymphatic drainage from the tonsil of the soft palate in pigs. J. Anat. 187, 491-495.

Berg, R., 1988: Kopf, Caput. In: Angewandte und topographische Anatomie der Haustiere, 3. Auflage (R. Berg ed). Jena: VEB Gustav Fischer Verlag.

Brandtzaeg, P., 2011: Immune functions of nasopharyngeal lymphoid tissue. Adv. Otorhinolaryngol. 72, 20-24.

Brandtzaeg, P., and R. Pabst, 2004: Let's go mucosal: Communication on slippery ground. Trends Immunol. 25, 570-577.

Breugelmans, S., C. Casteleyn, P. Simoens, and W. Van den Broeck, 2011a: Distribution of the lingual lymphoid tissue in domestic ruminants. Anat. Histol. Embryol. 40, 426-432.

Breugelmans, S., W. De Spiegelaere, C. Casteleyn, P. Simoens, and W. Van den Broeck, 2011b: Differences between the ovine tonsils based on an immunohistochemical quantification of the lymphocyte subpopulations. Comp. Immunol. Microbiol. Infect. Dis. 34, 217-225.

Breugelmans, S., W. Van den Broeck, K. Demeyere, E. Meyer, and P. Simoens, 2011c: Immunoassay of lymphocyte subsets in ovine palatine tonsils. Acta Histochem. 113, 416422.

Casteleyn C., D. Françoys, P. Simoens, and W. Van den Broeck, 2010b. The avian air sacs: Visualization in the chicken by means of the corrosion casting technique. Vlaams Diergen. Tijds. 79, 429-435.

Casteleyn, C. R., S. Breugelmans, P. Simoens, and W. Van den Broeck, 2008b: 306 Morphological and immunological characteristics of the bovine temporal lymph node and hemal node. Vet. Immunol. Immunopathol. 126, 339-350. 
308 Casteleyn, C. R., W. Van den Broeck, and P. Simoens, 2007: Histological characteristics and 309 stereological volume assessment of the ovine tonsils. Vet. Immunol. Immunopathol. 120, $310 \quad 124-135$.

311 Casteleyn, C., M. Cornelissen, P. Simoens, and W. Van den Broeck, 2010a: Ultramicroscopic 312 examination of the ovine tonsillar epithelia. Anat. Rec. 293, 879-889.

313 Casteleyn, C., P. Cornillie, P. Simoens, and W. Van den Broeck, 2008a: Stereological 314 assessment of the epithelial surface area of the ovine palatine and pharyngeal tonsils. Anat. $315 \quad$ Histol. Embryol. 37, 366-368.

316 Casteleyn, C., P. Simoens, and W. Van den Broeck, 2011a: Terminology of the tonsils. Anat. 317 Histol. Embryol. 40, 204-209.

318 Casteleyn, C., S. Breugelmans, P. Simoens, and W. Van den Broeck, 2011b: The tonsils 319 revisited: Review of the anatomical localization and histological characteristics of the 320 tonsils of domestic and laboratory animals. Clin. Dev. Immunol. (open access journal; doi: $10.1155 / 2011 / 472460)$.

Casteleyn, C., W. Van den Broeck, A. Gebert, B. Tambuyzer, S. Van Cruchten, and C. Van Ginneken, 2013: M cell specific markers in man and domestic animals: Valuable tools in vaccine development. Comp. Immunol. Microbiol. Infect. Dis. 36, 353-364.

Castenholz, A., 1984: Morphological characteristics of initial lymphatics in the tongue as shown by scanning electron microscopy. Scan. Electron Microsc. 1984/III, 1343-1352.

Castenholz, A., 1986: Corrosion cast technique applied in lymphatic pathways. Scan. Electron Microsc. 1986/II, 599-605.

329 Cesta, M. F., 2006: Normal structure, function, and histology of mucosa-associated lymphoid tissue. Toxicol. Pathol. 34, 599-608.

331 Chen, W., M. R. Alley, and B. W. Manktelow, 1989: Respiratory tract-associated lymphoid 332 tissue in conventionally raised sheep. J. Comp. Pathol. 101, 327-340. 
333 Fujisaka, M., O. Ohtani, and Y. Watanabe, 1996: Distribution of lymphatics in human 334 palatine tonsils: A study by enzyme-histochemistry and scanning electron microscopy on 335 lymphatic corrosion casts. Arch. Histol. Cytol. 59, 273-280.

336 Gille, U., 2008: Herz, Kreislauf- und Abwehrsystem, Angiologia. In: Anatomie für die 337 Tiermedizin, 2. Auflage (F.-V. Salomon, H. Geyer and U. Gille eds). Stuttgart: Enke $338 \quad$ Verlag.

339 Girard, J.-P., and T. A. Springer, 1995: High endothelial venules (HEV's): specialized 340 endothelium for lymphocyte migration. Immunol. Today 16, 449-457.

341 Grau-Karlsbad, H., 1974: Das Lymphgefäßsystem. In: Ellenberger/Baum: Handbuch der 342 vergleichenden Anatomie der Haustiere, 18. Auflage (O. Zietzschmann, E. Ackerknecht 343 and H. Grau eds). Berlin: Springer-Verlag.

344 Heath, T. J., and H. J. Spalding, 1987: Pathways of lymph flow to and from the medulla of 345 lymph nodes in sheep. J. Anat. 155, 177-188.

346 Heath, T. J., R. L. Kerlin, and H. J. Spalding, 1986: Afferent pathways of lymph flow within the popliteal node in sheep. J. Anat. 149, 65-75.

Hodde, K.C., 1981: Cephalic vascular patterns in the rat: A scanning electron microscopic (SEM) study of casts. PhD dissertation, University of Amsterdam.

Indrasingh, I., G. Chandi, and S. Vettivel, 2002: Route of lymphocyte migration through the high endothelial venule (HEV) in human palatine tonsil. Ann. Anat. 184, 77-84.

Konerding, M. A., 1991: Scanning electron microscopy of corrosion casting in medicine. Scanning Microsc. 5, 851-865.

354 König, H. E., J. Sautet, and H.-G. Liebich, 2002: Verdauungsapparat (Apparatus digestorius). 355 In: Anatomie der Haussäugetiere - Lehrbuch und Farbatlas für Studium und Praxis, Band 356 II Organe, Kreislauf- und Nervensystem (H. E. König and H.-G. Liebig eds). Stuttgart: Schattauer. 
Kuper, C. F., P. J. Koornstra, D. M. H. Hameleers, J. Biewenga, B. J. Spit, A. M. Duijvestijn, P. J. C. van Breda Vriesman, and T. Sminia, 1992: The role of nasopharyngeal lymphoid tissue. Immunol. Today 13, 219-224.

361 Kuper, C.F., 2006: Histopathology of mucosa-associated lymphoid tissue. Toxicol. Pathol. 34, 609-615.

Liebler-Tenorio, E., and R. Pabst, 2006: MALT structure and function in farm animals. Vet. Res. 37, 257-280.

Lowden, S., and T. Heath, 1992: Lymph pathways associated with Peyer's patches in sheep. J. Anat. 181, 209-217.

Lowden, S., and T. Heath, 1993: Lymphatic drainage from the distal small intestine in sheep. J. Anat. 183, 13-20.

Lowden, S., and T. Heath, 1994: Ileal Peyer's patches in pigs: intercellular and lymphatic pathways. Anat. Rec. 239, 297-305.

371 Mair, T. S., E. H. Batten, C. R. Stokes, and F. J. Bourne, 1987: The histological features of the immune system of the equine respiratory tract. J. Comp. Pathol. 97, 575-586.

Martin, P., and W. Schauder, 1938: Lymphgefäßsystem des Rindes. In: Lehrbuch der Anatomie der Haustiere, III. Band, III. Teil: Harn- und Geslechtsorgane, Blut- und Lymphgefäßsystem, Nervensystem, Haut- und Sinnesorgane der Hauswiederkäuer (P. Martin and W. Schauder eds). Stuttgart: Verlag von Schickhardt \& Ebner.

Maunsell, F., M. B. Brown, J. Powe, J. Ivey, M. Woolard, W. Love, and J. W. Simecka, 2012: Oral inoculation of young dairy calves with Mycoplasma bovis results in colonization of tonsils, development of otitis media and local immunity. PLoS One 7, e44523.

Murakami, T., T. Itoshima, K. Hitomi, A. Ohtsuka, and A. L. Jones, 1984: A monomeric methyl and hydroxypropyl methacrylate injection medium and its utility in casting blood 
capillaries and liver bile canaliculi for scanning electron microscopy. Arch. Histol. Jpn. 47, 223-37.

384 Murphy, K., P. Travers, and M. Walport, 2008: Manipulation of the immune response. In: 385 Janeway's Immunobiology, 7th edn. (K. Murphy, P. Travers and M. Walport eds). 386 London: Garland Science.

387 Ohtani, O., and T. Murakami, 1990: Organization of the lymphatic vessels and their 388 relationships to the blood vessels in the rabbit Peyer's patches. Arch. Histol. Cytol. 53, $155-164$.

Regoli, M., C. Borghes, E. Bertelli, and L. Comparini, 1995: Arrangement of the small intestine lymphatic network in the Peyer's patches of the mouse. A light and transmission electron microscopic study. Ann. Anat. 177, 229-235.

Rothkötter, H. J., C. Hriesi, and R. Pabst, 1995: More newly formed T than B lymphocytes leave the intestinal mucosa via lymphatics. Eur. J. Immunol. 25, 866-869.

Russo, D., C. Mongardi Fantaguzzi, G. Di Guardo, P. Clavenzani, G. Lalatta Costerbosa, C. Ligios, and R. Chiocchetti, 2009: Characterization of sheep (Ovis aries) palatine tonsil innervation. Neuroscience 161, 813-826.

398 Saar, L. I., and R. Getty, 1975: Ruminant lymphatic system: part II Ovine. In: Sisson and 399 Grossman's: The Anatomy of the Domestic Animals, 5th edn. (R. Getty ed). London: W. B. Saunders Company.

401 Schreuder, B. E. C., L. J. M. van Keulen, M. E. W. Vromans, J. P. M. Langeveld, and M. A. 402 Smits, 1998: Tonsillar biopsy and $\mathrm{PrP}^{\mathrm{Sc}}$ detection in the preclinical diagnosis of scrapie. 403 Vet. Rec. 142, 564-568.

404 Schummer, A., H. Wilkens, B. Vollmerhaus, and K.-H. Habermehl, 1981: The Circulatory 405 System, the Skin, and the Cutaneous Organs of the Domestic Mammals. In: The Anatomy 
of the Domestic Animals (R. Nickel, A. Schummer and E. Seiferle eds). Berlin: Verlag Paul Parey.

408

409

410

Stefanov, M., J. D. Kim, M. H. Nam, and Soh K. S., 2013: New approach of corrosion casting using direct injection of mercox into the parenchyma of different organs. Anat. Rec. (Hoboken) 296, 724-725.

Tizard, I. R., 2013: The use of vaccines. In: Veterinary Immunology, 9th edn. (I. R. Tizard ed). St. Louis: Elsevier.

Toppets, V., J. Piret, N. Kirschvink, F. Lantier, I. Lantier, P. Berthon, G. Daube, L. Massart, L. Grobet, and N. Antoine, 2012: Neuroimmune connections in ovine pharyngeal tonsil: potential site for prion neuroinvasion. Cell Tissue Res. 348, 167-176.

van Keulen, L. J. M., A. Bossers, and F. Van Zijderveld, 2008: TSE pathogenesis in cattle and sheep. Vet. Res. 39, 24-35.

Vollmerhaus, B., 1976: Lymphatisches System. In: Lehrbuch der Anatomie der Haustiere, Band III Kreislaufsystem, Haut und Hautorgane (R. Nickel, A. Schummer and E. Seiferle eds). Berlin: Verlag Paul Parey.

von Waldeyer-Hartz, W., 1884: Ueber den lymphatischen Apparat des Pharynx. Dtsch. Med. Wochenschr. 10, 313.

Zuercher, A. W., 2003: Upper respiratory tract immunity. Viral Immunol. 16, 279-289.

\section{Figure legends}

Fig. 1. Paramedian section through the ovine head showing a medial view of the right side of the nasopharynx. After Indian ink was interstitially injected into the tubal tonsil (1), black carbon particles spread through lymph vessels (arrows) that extended towards the medial retropharyngeal lymph node (2). Some anatomical landmarks, such as the soft palate (3) and the epiglottis (4) are additionally indicated. B: Medial retropharyngeal lymph node receiving 
431 carbon particles via three afferent lymph vessels (alv) giving off primary branches (pb) that 432 subsequently divide into secondary branches $(\mathrm{sb})$ which finally give off terminal branches (tb) 433 that enter the subcapsular sinus (ss).

Fig. 2. Histological section through the ovine pharyngeal tonsil after interstitial injection of

436 Indian ink. A: Carbon particles are visible in the interfollicular lymph vessel network (iln) 437 which surrounds the lymphoid follicles (F). Larger lymph vessels (ILV) are present in the connective tissue core of the tonsil. B: Higher magnification showing the abundant presence of carbon particles in the interfollicular lymph vessel network (iln) and lymph sinuses surrounding the lymphoid follicles (F). The interfollicular blood vessels (arrows) are not

441 loaded with carbon particles. Notice the intrafollicular presence of carbon particles that are 442 not enclosed by endothelium-lined vessels (arrowheads).

444 Fig. 3. SEM views of the lymph vessel architecture of the ovine pharyngeal tonsil. A: Spaces 445 previously occupied by lymphoid follicles (F) are surrounded by numerous sacculated lymph 446 sinuses (sl) that drain into interfollicular lymph vessel networks (iln). Small lymph vessels 447 (sLV) emerge from this network. B: Higher magnification of the interfollicular lymph vessel 448 network (iln) showing the imprints of lymphoid cells (arrows) present in the interfollicular 449 areas. C: The small lymph vessels (sLV) that emerge from the interfollicular lymph vessel 450 network (iln) surrounding the lymphoid follicles (F) drain into large lymph vessels that travel 451 through the connective tissue core of the tonsil. D: A larger lymph vessel (ILV) characterized 452 by the presence of many, often V-shaped, constrictions (arrows) corresponding to lymph 453 vessel valves courses through interstitial spaces (i). 
455 Fig. 4. SEM images of the lymph vessel architecture of the ovine palatine tonsil. A: The 456 locations of macerated lymphoid follicles (F) can be recognized as round impressions. Each 457 lymphoid follicle is surrounded by the interfollicular lymph vessel network (iln). Some lymph 458 vessels (LV) are additionally indicated. B: Higher magnification of the impression of the 459 lymphoid follicle encircled in A. Sacculated lymph sinuses (sl) surrounding the lymphoid 460 follicle are prominent. They drain into the interfollicular lymph vessel network (iln).

461

462 Fig. 5. SEM view of the lymph vessel architecture of the ovine paraepiglottic tonsil. 463 Sacculated lymph sinuses (sl) surrounding the lymphoid follicles (F) drain into the 464 interfollicular lymph vessel network (iln) which is connected by small calibre lymph vessels 465 (sLV) to larger lymph vessels (ILV).

466

467 Fig. 6. SEM images of the lymph vessel architecture of the ovine tonsil of the soft palate. A: 468 No imprints of lymphoid follicles can be seen in this diffusely organized tonsil. The 469 subepithelial interstitial spaces (i) drain into small lymph vessels (sLV), which in turn flow 470 into large lymph vessels (ILV) that travel through the nasopharyngeal mucosa. B: Higher 471 magnification of the subepithelial interstitial spaces (i) that drain into a small lymph vessel 472 (sLV). 


\section{$473 \quad$ Figures}

474
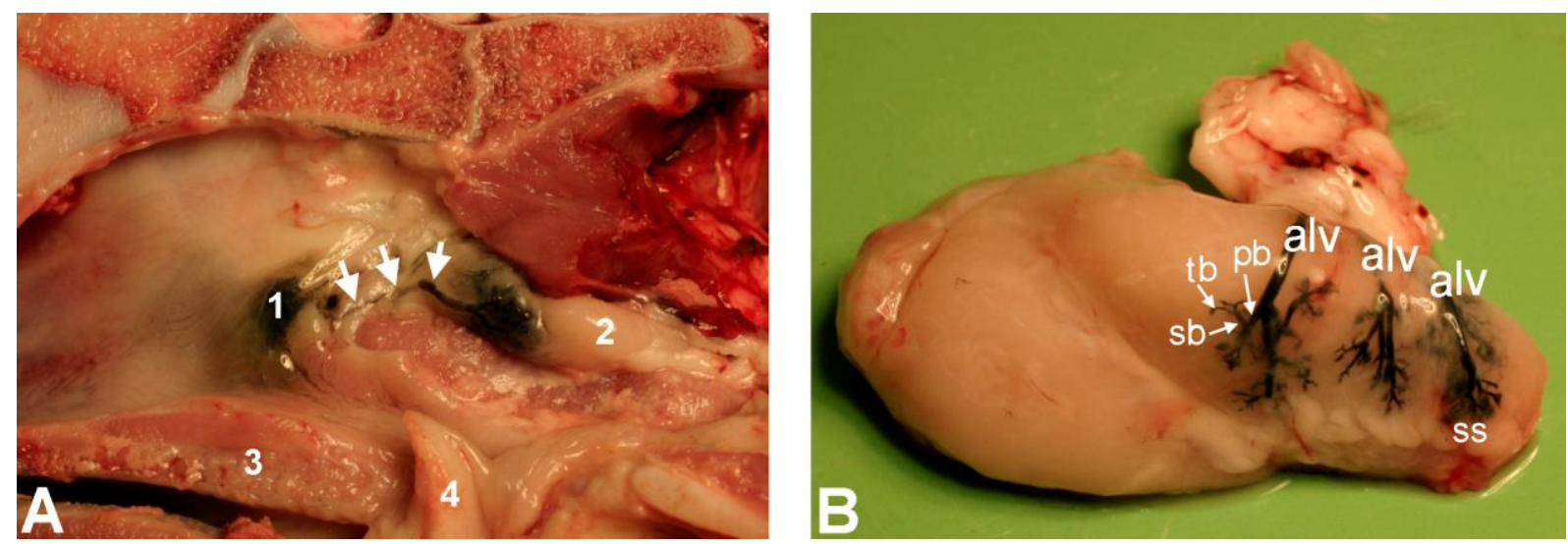

$475 \quad$ Fig. 1

476
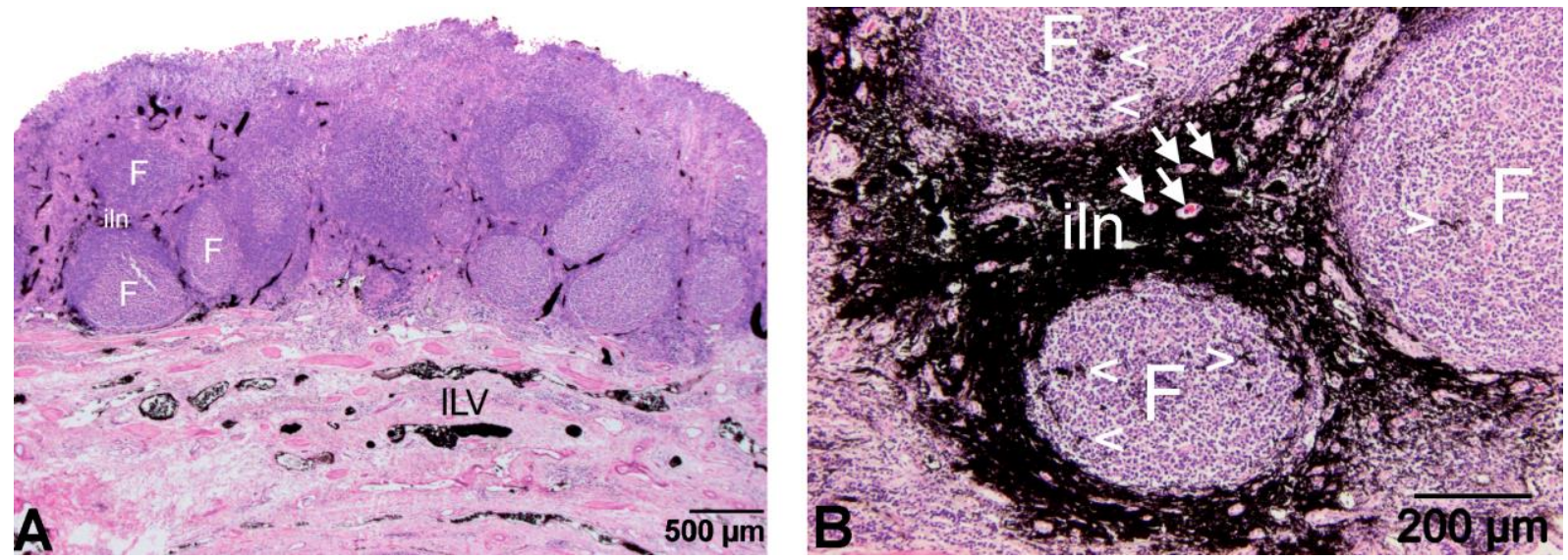

477

A

$50 \overline{\mu \mathrm{m}}$

$478 \quad$ Fig. 2

479 


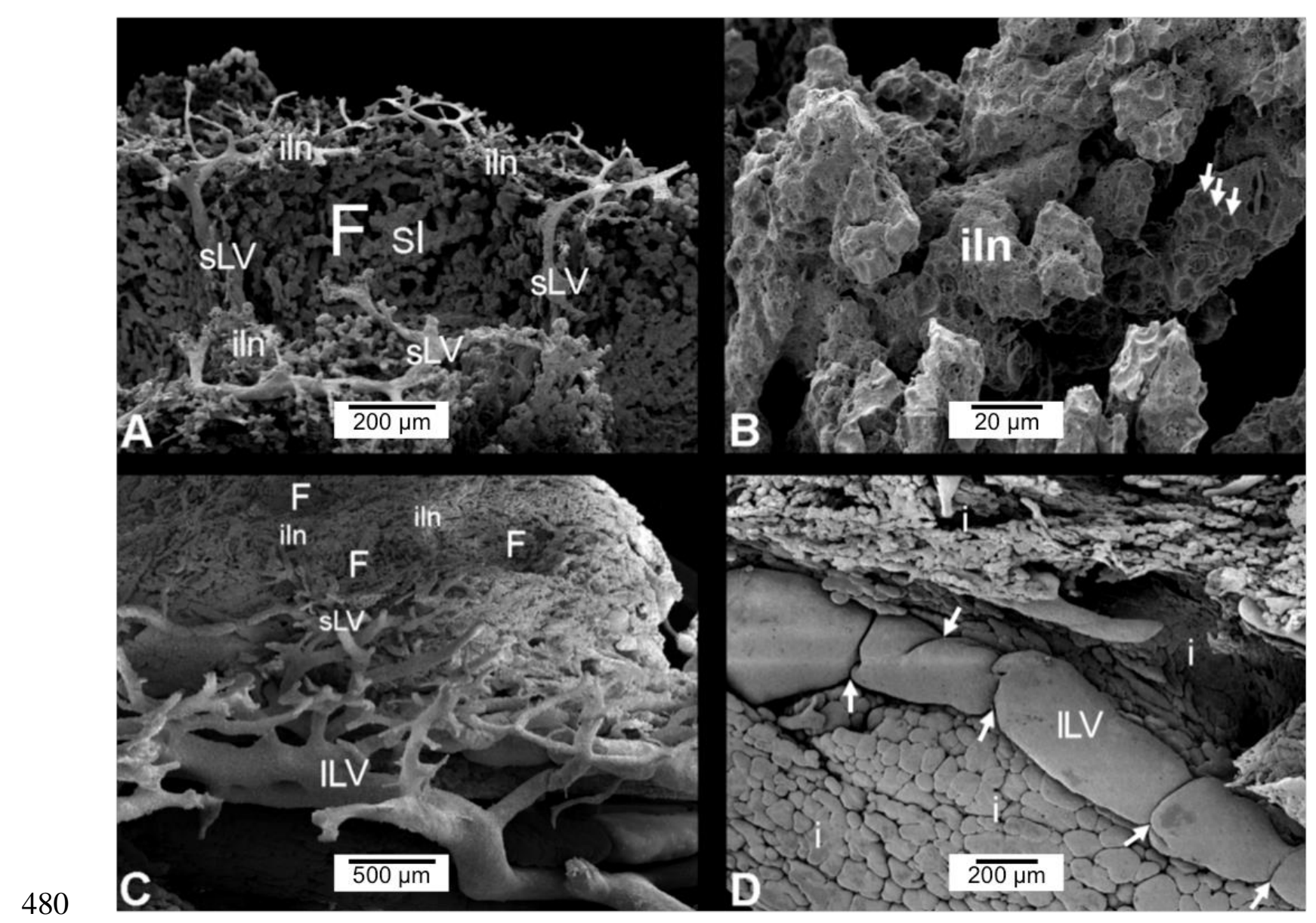

$481 \quad$ Fig. 3

482

483
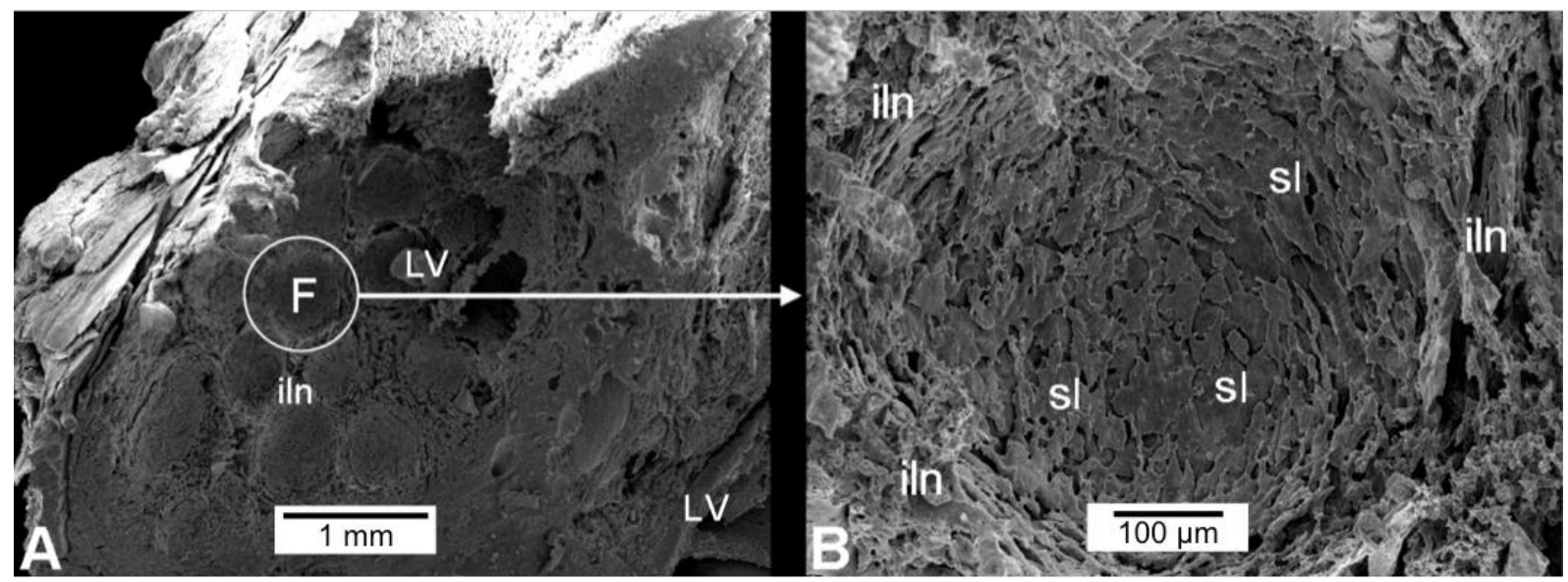

$484 \quad$ Fig. 4 


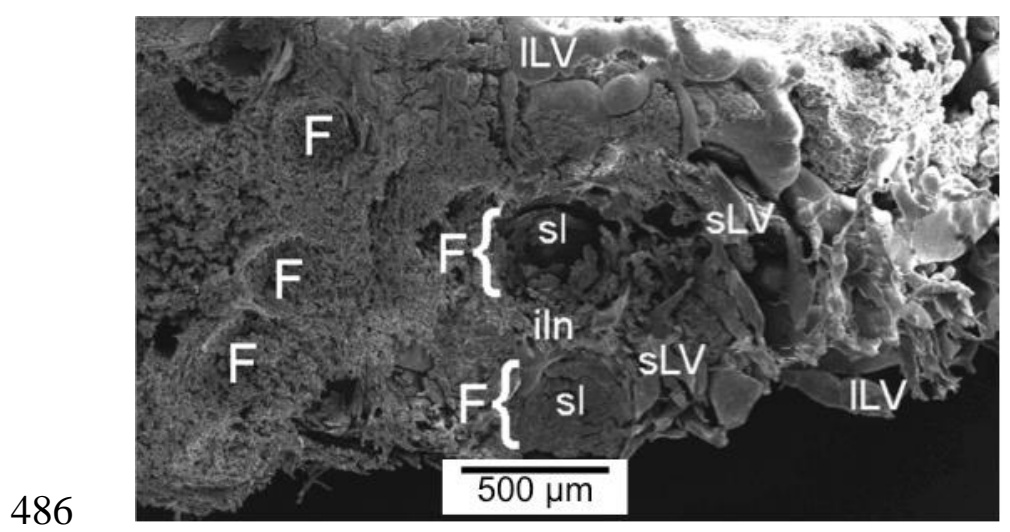

$487 \quad$ Fig. 5

488

489
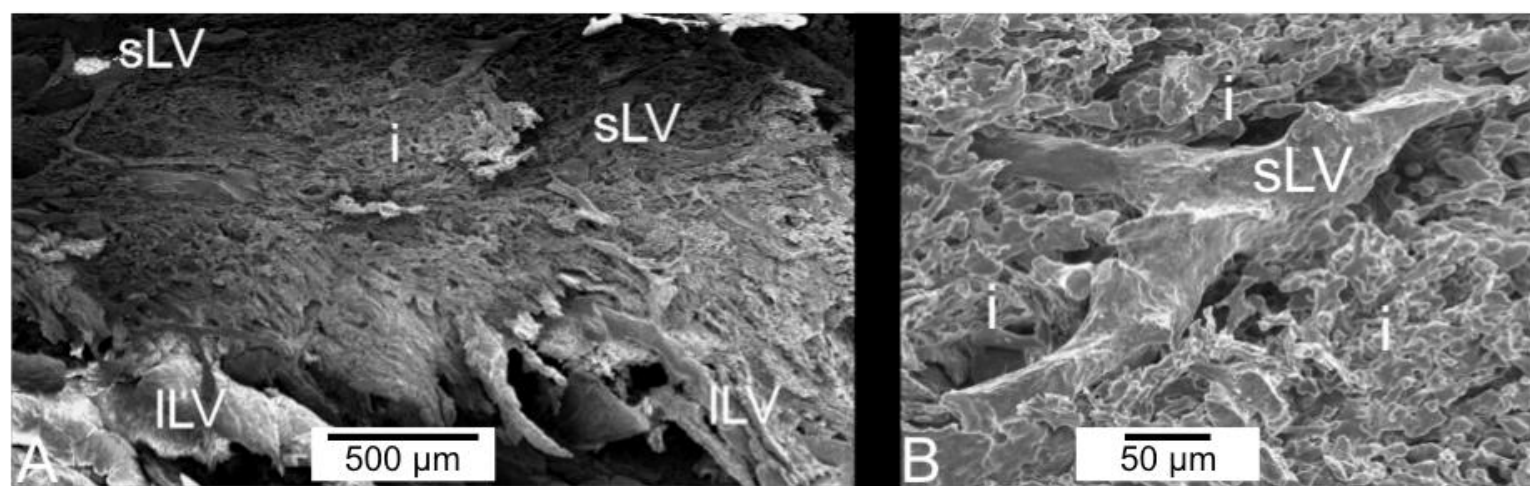

$490 \quad$ Fig. 6 